\title{
Postverbal subjects and nuclear pitch accent in Italian wh-questions
}

\section{Bocci, Giuliano}

de Gruyter

2018

Bocci , G \& Cruschina , S 2018 , Postverbal subjects and nuclear pitch accent in Italian wh-questions . in R Petrosino, $\mathrm{P}$ Cerrone \& $\mathrm{H}$ van der Hulst (eds), From Sounds to Structures : Beyond the Veil of Maya . Studies in Generative Grammar [SGG] , no. 135 , de pÿGruyter, Berlin , pp. 467494 . https://doi.org/10.1515/9781501506734

http://hdl.handle.net/10138/308644

https://doi.org/10.1515/9781501506734

acceptedVersion

Downloaded from Helda, University of Helsinki institutional repository.

This is an electronic reprint of the original article.

This reprint may differ from the original in pagination and typographic detail.

Please cite the original version. 


\title{
Postverbal subjects and main prominence in Italian wh-questions*
}

\author{
Giuliano Bocci \\ University of Geneva
}

\author{
\& Silvio Cruschina \\ University of Vienna
}

\author{
Ad Andrea, per tutto quello che ci ha insegnato, \\ trasmesso e cucinato
}

\section{Introduction}

In his seminal paper on the relationship between word order alternations, information structure, and phonology in Italian, Calabrese (1982) discusses two generalizations that, despite their relevance to the understanding of the derivation and prosody of wh-questions, have largely escaped the attention of the subsequent linguistic literature: ${ }^{1}$

(a) Subject inversion in embedded clauses under long distance movement: In direct wh-questions, subjects tend to appear postverbally not only in matrix clauses in case of short wh-movement, but also in the embedded clauses from which the wh-element is extracted via long distance movement to the matrix clause (i.e. long wh-movement);

(b) Nuclear pitch accent (NPA) assignment: In wh-questions, NPA is generally assigned to the verb.

While several other syntactic and phonological aspects of focus constituents in declarative sentences have later been developed by other scholars, these two generalizations have somehow been relegated to a pool of mysteries that still revolve around the grammatical properties of wh-questions. The main aim of the present paper is to provide experimental evidence in support of the first empirical generalization and to redefine this property in the light of more recent theoretical developments. The second generalization will also be discussed, especially for what concerns its relevance to the understanding of real nature of the embedded subject inversion. However, for this latter generalization, we will mostly rely on the findings reported and examined in Bocci, Bianchi \& Cruschina (2017) (henceforth, BBC 2017).

Following Calabrese (1982), we show that subject inversion and NPA assignment in Italian wh-questions are the reflexes of the derivational history

\footnotetext{
* We would like to thank Valentina Bianchi and Lucia Pozzan for invaluable help and discussion. Giuliano Bocci's research was supported by the ERC Advanced Grant 340297 SynCart.

${ }^{1}$ Note that the two generalizations do not hold for Italian yes/no-questions. Even if it used to be a feature of Old Italian (cf. Munaro 2010), modern Italian yes/no-questions do not require subject inversion, either in the matrix or in an embedded clause; nor do they display any special prosodic pattern with respect to the placement of NPA.
} 
of the wh-movement, and, accordingly, the result of a direct interaction between the syntactic and the phonological component. Our analysis, however, takes a different view on the specific mechanisms through which syntax tailors and delivers its instructions to prosody.

The structure of this chapter is the following. We first illustrate the phenomenon of subject inversion in Italian wh-questions ( $\$ 2)$. In Section 3, we present the results of a syntactic experiment on the distribution of subjects in the embedded clause of wh-questions. Our analysis is presented in Section 4, where we directly related the syntactic and prosodic peculiarities of Italian whquestions to the successive cyclic nature and to the intermediate positions of wh-movement. We show that while subject inversion is a phenomenon that involves the edge of the C-phrase, the assignment of NPA additionally involves the $v \mathrm{P}$-edge. We then attempt to capture the observed patterns and to provide further support to our analysis by comparing direct and indirect wh-questions with respect to both subject inversion and their prosodic properties (§5). A summary and some final remarks finally close the chapter.

\section{Subject inversion in wh-questions}

Subject inversion in interrogative environments is a syntactic property common to many languages. In Italian, however, we do not observe the same rigid subject inversion pattern as in English or in German: when referred to the Italian facts, thence, the term itself might be misleading. The essential property of Italian wh-questions is the adjacency requirement between the wh-phrase and the verb. This has direct repercussions on the other constituents in the sentence, including the subject, which cannot appear in a preverbal position. It is important to note, however, that the subject in Italian does not necessarily undergo inversion: in fact, it can be omitted or dislocated to the left. In neutral contexts where the subject does not have a valid antecedent in the context and resists dislocation or omission, the subject will tend to appear in a postverbal position: this is what we mean with subject inversion in this paper. ${ }^{2}$

In what follows, we will first describe the phenomenon of subject inversion in the matrix clause of wh-questions, with short-distance movement. Subject inversion in embedded clauses in combination with long-distance movement will be discussed in the next subsection.

\subsection{Matrix subject inversion and short-distance movement}

It is well known that, in Italian wh-questions with bare wh-elements, neither subjects nor other constituents can intervene between the wh-phrase and the

\footnotetext{
${ }^{2}$ See Cardinaletti $(2001,2002)$ for evidence that postverbal subjects are not necessarily right-dislocated, but can stay in their base-generated position.
} 
verb - the subject, for instance, must occur postverbally, as shown in (1) (see Calabrese 1982, Rizzi 1996, 2001, Bocci 2013, a.o.): ${ }^{3}$

$$
\begin{aligned}
& \text { a. Chi ha visto Mario? } \\
& \text { who has seen Mario } \\
& \text { b. } \text { Chi Mario ha visto? } \\
& \text { who Mario has seen } \\
& \text { 'Who did Mario see?' }
\end{aligned}
$$

Calabrese (1982) treats this restriction as a consequence of a phonological requirement that imposes the wh-phrase and the verb to form a single intonational phrase. Focal elements, including wh-phrases, receive a $[\mathrm{F}]$ feature ([N] for 'new' in Calabrese's original formulation) from the verb and must be string-adjacent to it: the phonological group consisting of the verb and the $[\mathrm{F}]-$ marked elements will form a single and independent intonational phrase that will constitute the main intonational phrase of the sentence whose rightmost constituent is thus assigned NPA. In wh-questions, the wh-phrase in the CP inherits $[\mathrm{F}]$ from its trace in the base-generation position and must be adjacent to the verb. Any potential intervener must be syntactically displaced. For Calabrese, therefore, the same phonological requirement is responsible for both subject inversion and NPA assignment.

Different accounts, mainly in syntactic terms, have been proposed to explain the adjacency requirement in more recent years. According to Rizzi (1996 et seq.), wh-movement is driven by the Wh-Criterion, ${ }^{4}$ which requires a wh-phrase carrying the feature [wh] to be in a Spec-Head agree-relation with a head endowed with the same feature. This criterial configuration must be satisfied in a dedicated CP-projection of the left periphery, namely, FocP. The head that carries the feature $[\mathrm{wh}]$ in wh-questions is T: thus, the wh-phrase ends up in Spec/FocP, while T moves to $\mathrm{Foc}^{\mathrm{o}}$ and brings the [wh] feature along with it. In the criterial approach, therefore, T-to-C movement takes place in order to yields the Spec-Head configuration which, in turn, ensures the adjacency between the two elements and prevents any other constituent from interposing between them (for a different technical implementation of this analysis, see Rizzi 2006). More recently, adopting the view that there are several preverbal subject positions specialized for different types of subject (see Cardinaletti

\footnotetext{
${ }^{3}$ Cardinaletti (2007) shows that certain elements, in particular specific types of adverb, can intervene between the wh-phrase and the verb. For simplicity, we here describe the adjacency requirement in its traditional terms and refer to her work for the relevant exceptions.

${ }^{4}$ The Wh-Criterion is one of the Criteria that require a phrase with feature $[\alpha]$ to be in a Spec-Head configuration with a functional head carrying [ $\alpha]$. See Rizzi (2006) for more details.
} 
1997, 2004), the intervention restriction has been selectively limited to the projection SubjP - that is, the project that hosts strong and overt preverbal subjects functioning as subjects of the predication - as opposed to weak or null pronouns which occur in Spec/TP or in lower positions. More specifically, it has been proposed that T-to-C movement prevents the subject from moving to SubjP (cf. Rizzi \& Shlonsky 2007): the subject must therefore either remain in a lower position or be dislocated.

A different position is taken by Cardinaletti (2007). While, on the one hand, she still assumes the unavailability of Spec/SubjP in wh-questions, on the other, Cardinaletti argues against the hypothesis that the wh-phrase and the verb occur in one and the same projection. She claims that "only subjects in specSubjP are excluded from occurring between the wh-phrase and the verb in wh-questions, whereas subjects in specTP (or lower subject positions [...]) are permitted" (Cardinaletti 2007: 66).

Irrespective of the motivation behind the ban on intervening subjects in wh-questions, these syntactic approaches only address the issue with respect to matrix wh-questions, ${ }^{5}$ neglecting what happens within the left periphery of a possible embedded clause from which wh-movement takes place. As observed by Calabrese (1982), in fact, subject inversion occurs both with short- and longdistance movement. ${ }^{6}$ Moreover, the syntactic approaches do not address the issue of NPA assignment and, in fact, their explanation does not offer any element to account for the special prosodic contour of wh-questions.

\subsection{Embedded subject inversion and long-distance movement}

As already mentioned, Calabrese (1982: 39-40) makes an important empirical observation: when the wh-phrase is moved from an embedded clause, the embedded subject must appear postverbally:
hai detto che
Carlo ha fatto? what thing him.DAT have.2SG said that
Carlo has done
b.

Che cosa gli hai detto che ha fatto Carlo?
what thing him.DAT have.2sg said that has done Carlo
'What did you say Carlo has done?'

The wh-phrase che cosa ('what') in (2) is extracted from the embedded clause of the direct wh-question. In combination with this long-distance movement, a preverbal embedded subject proves rather marginal (cf. 2a), while subject

\footnotetext{
${ }^{5}$ Several observations about the special properties of indirect wh-questions are discussed in Rizzi (2001).

${ }^{6}$ This observation is also discussed in Torrego $(1983,1984)$, where subject inversion in Spanish wh-questions with long-distance movement is investigated. Her analysis will be considered in the next section.
} 
inversion would make the sentence fully grammatical. Calabrese relates this constraint to the phonological requirement that imposes the phonological phrase containing the verb and the phonological phrase of the constituent bearing the $[\mathrm{F}]$ feature to form the main intonational phrase of the sentence. ${ }^{7} \mathrm{In}$ the case of long-distance movement (2b), the embedded verb containing the trace of the wh-chain will be phrased within the same intonational phrase (i.e. IP) as the F-marked constituent: ${ }^{8}$

(2') b. [[Che cosa $\left.{ }_{\Phi}\right]$ [gli hai detto $\left.\Phi_{\Phi}\right]\left[\right.$ che ha fatto $\left.\left.{ }_{\Phi}\right][t]_{\text {IP }}\right]\left[\right.$ Carlo $\left._{\Phi}\right]$ ?

In other words, when the wh-phrase is extracted from an embedded clause, the main intonational phrase of the sentence must include the head and the foot (i.e. the trace) of the wh-chain, as well as both the embedded and the matrix verb: adjacency throughout all these elements is required, and NPA is assigned to the rightmost (phonologically non-null) element within this intonational phrase, i.e. to the embedded lexical verb. As a consequence of the phonological constraint, the embedded subject Carlo must be right dislocated or marginalized (cf. 2a) (see also Antinucci \& Cinque 1977, Cardinaletti 2002, 2007). No content elements other than verbs can be included within this sequence.

Around the same time the same phenomenon was observed by Torrego (1983, 1984) for Spanish. Unlike Calabrese, however, Torrego analyses embedded subject inversion in wh-questions as a syntactic phenomenon in nature: a direct reflex of successive cyclic movement. In particular, she argues that when an operator such as the wh-phrase moves to Spec/CP, the verb must reach the head of $\mathrm{CP}$ in order to establish the required configuration with the wh-element. In her account, therefore, T-to-C movement also takes place in case of long-extraction:

(3) a. ¿Qué querían esos dos?

what wanted these two

'What did those two want?'

b. * Qué esos dos querían?

(Torrego 1984: 103)

\footnotetext{
${ }^{7}$ This intuition has many aspects in common with the recent theory of wh-movement ‘Contiguity Theory' by Norvin Richards (2010, 2016).

${ }^{8}$ The relevant tone is assigned to lexical heads only (Calabrese 1982: 19, therefore excluding auxiliaries and complementizers (see also Nespor \& Vogel 1986).
} 
(4) a. ¿Qué pensaba Juan que le había dicho Pedro que what thought John that him had told Peter that había publicado la revista $[\mathrm{t}]$ ?

had published the journal

'What did John think that Peter had told him that the journal had published?'

b. * ¿Qué pensaba $\underline{\text { Juan }}$ que Pedro le había dicho que what thought John that Peter him had told that la revista había publicado? the journal had published

(Torrego 1984: 109)

Under Torrego's analysis, T-to-C-movement applies not only in the matrix clause (3), but also in all embedded left peripheries hosting the wh-phrases in intermediate positions on its way to the final (matrix) landing site (4): subject inversion takes place along the whole movement path (see also Henry 1995 on Belfast English). In our analysis, we put together elements of both analyses, i.e. Calabrese's phonological account and Torrego's syntactic account. Before outlining our proposal in detail (cf. § 4), let us now go back to Italian and let us consider some empirical evidence in support of embedded subject inversion.

\section{The distribution of embedded subjects: The syntactic experiment}

In order to experimentally support Calabrese's observation on embedded subject inversion, we carried out a forced-choice experiment where participants had to express their preference for the pre- or post-verbal placement of the subject in the complement clause of direct wh-questions. The design, the methodology and the results of this experiment are discussed in this section.

\subsection{Design and methodology}

We carried out a web-based forced choice experiment (hosted by Ibex Farm). 59 Italian native speakers, recruited via Facebook, volunteered the experiment. Two independent binary factors in a $2 * 2$ factorial design were tested:

a) type of wh-dependency: long (from embedded clause) vs. short extraction (from matrix clause)

b) type of verb in the embedded clause: transitive vs. intransitive

The factor (a) is directly related to the issue of subject inversion in whquestions, while factor (b) was included in order to verify if, especially in case of long extraction from an embedded clause, the type of verb could have any influence on the position of the embedded subject.

We tested 24 items. Type of wh-dependency was manipulated between items, while verb-type was manipulated within items. In other words, we tested 12 items with intransitive verbs and 12 items with transitive verbs. Each item 
included the variants with the long and short distance movement. For the resulting 48 experimental sentences $(12$ items $* 2$ verb types $* 2$ dependency types), we then created the two alternative versions that minimally differ with respect to the position of the subject in the embedded clause: either preverbal or post-verbal. This amounts to a total of 96 stimuli.

The two independent factors were manipulated within participants and the experimental sentences were arranged in a Latin-square design. We divided the experimental sentences in 4 lists so that each list included one experimental sentence per item. Each list consisted of 24 experimental sentences (with the two alternatives) and 24 fillers.

Each trial started with a brief description of a hypothetical context. The subject of the target sentences was never mentioned in this introductory context in order to avoid that the postverbal, sentence-final subject could be interpreted as given and, hence, as syntactically right-dislocated. The matrix verb was always the verb of saying dire. The stimuli were presented in a pseudorandomized order.

In each trial, two sentences which varied only with respect to the position of the subject were presented and the participants were asked to express their preference for either version. The participants had to express their preference for either version. It is also important to emphasize that the target sentences were also controlled with respect to the type of wh-dependency: they were nearly identical in the long and short movement condition, except for the position of a dative clitic pronoun which forced one interpretation against the other. Moreover, for each item the short of and the long distance sentences were introduced by the same context. Let us see some examples. In (5) and in (6), we have an intransitive verb (disobbedire 'disobey') in combination with short (5) and long movement (6), respectively. The two sentences in (5) and (6) only differ with respect to the position of the embedded subject: the a-sentences contain a preverbal subject, while the b-sentences include a postverbal subject.

\section{(5) SHORT MOVEMENT, INTRANSITIVE V}

Ad un consiglio dei docenti, si tirano le somme e si decidono $i$ voti in condotta. Ma ci sono alcuni disaccordi tra colleghi, e la direttrice, per assicurarsi di aver capito bene, chiede a Lucia, l'insegnante di ginnastica:

'At a meeting, teachers take stock and decide the grades for behaviour. There are some disagreements among colleagues, and the principal, to make sure that she understood correctly, asks Lucia, the physical education teacher:'
a. A chi hanno detto che Giulio ti ha disobbedito?
b. A chi hanno detto che ti ha disobbedito Giulio? (VS) to who have.3PL said that Giulio you has disobeyed Giulio 


\section{(6) LONG MOVEMENT, INTRANSITIVE V}

Ad un consiglio dei docenti, si tirano le somme e si decidono i voti in condotta. Ma ci sono alcuni disaccordi tra colleghi, e la direttrice, per assicurarsi di aver capito bene, chiede a Lucia, l'insegnante di ginnastica:

'At a meeting, teachers take stock and decide the grades for behaviour. There are some disagreements among colleagues, and the principal, to make sure that she understood correctly, asks Lucia, the physical education teacher:'

a. A chi ti hanno detto che Giulio ha disobbedito?

to who you have.3PL said that Giulio has disobeyed

b. A chi ti hanno detto che ha disobbedito Giulio? to who you have.3pl said that has disobeyed Giulio

The same design and structure was maintained for the 12 items involving a transitive embedded verb, such as insultare 'insult' in (7) and in (8):

\section{(7) SHORT MOVEMENT, TRANSITIVE V}

Francesco è il nuovo insegnante di filosofia di un liceo. Durante il primo giorno di lavoro, un collega gli racconta un episodio spiacevole sul quale non è ancora stato preso nessun provvedimento. Francesco, un po' perplesso, gli chiede:

'Francesco is the new philosophy teacher in a high school. During the first day of work, a colleague tells him about an unpleasant incident, for which no disciplinary action has yet been taken. Francesco, a bit puzzles, asks him:'

a. A chi hai detto che gli studenti ti hanno insultato? to who have.2SG said that the students you have.3PL insulted

b. A chi hai detto che ti hanno insultato gli studenti? to who have.2SG said that you have.3PL insulted the students

\section{(8) LONG MOVEMENT, TRANSITIVE V}

Francesco è il nuovo insegnante di filosofia di un liceo. Durante il primo giorno di lavoro, un collega gli racconta un episodio spiacevole sul quale non è ancora stato preso nessun provvedimento. Francesco, un po' perplesso, gli chiede:

'Francesco is the new philosophy teacher in a high school. During the first day of work, a colleague tells him about an unpleasant incident, for which no disciplinary action has yet been taken. Francesco, a bit puzzles, asks him:'

a. Chi hai detto che gli studenti hanno insultato?

who have.2SG said that the students have.3PL insulted

b. Chi hai detto che hanno insultato gli studenti?

who have.2SG said that have.3PL insulted the students 
In short movement contexts, the wh-phrases is an argument of the matrix verb and thus undergoes short-distance movement, while in long distance contexts the wh-phrase is an argument of the embedded verb and therefore gives rise to a long-distance dependency. The clitic pronoun $t i$ 'to you' in sentences like those (7) was necessary to avoid that the wh-phrase could be interpreted as the dative argument of the matrix verb dire 'say'.

\subsection{The results}

As already mentioned, the results of the syntactic experiment confirm Calabrese's observation: the embedded subjects of wh-questions tend to appear postverbally when the wh-phrase is extracted from the embedded clause. The results are illustrated in Fig.1 with respect to the first factor, namely, type of wh-dependency. Crucially, this tendency only emerges with long-movement contexts, i.e. when the wh-phrase is extracted from within the embedded clause, where postverbal subjects are preferred in the $79 \%$ of the cases. In shortmovement contexts, by contrast, subjects of the embedded are preferred in preverbal position (67\%):

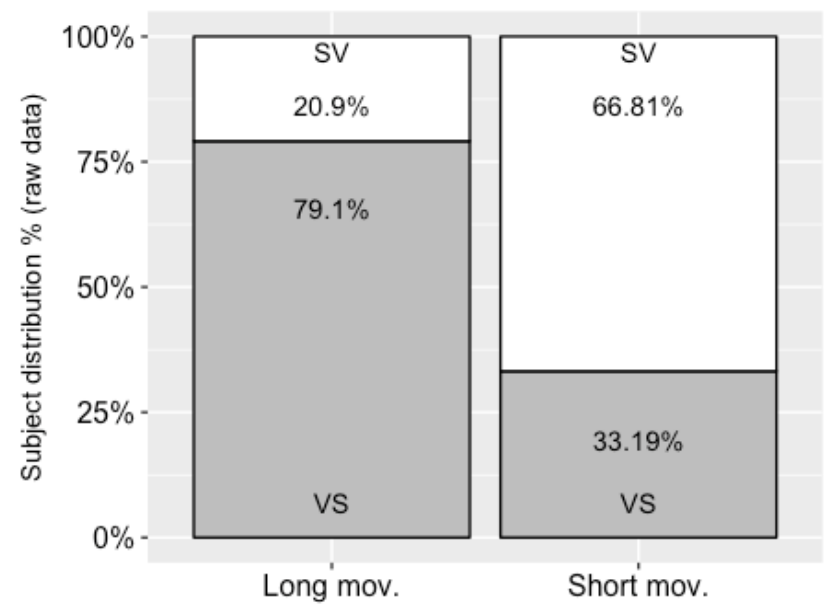

Figure 1: Preferences of SV vs. VS across type of dependency

If we integrate the second factor into this picture, it results that very little changes. See Figure 2: 


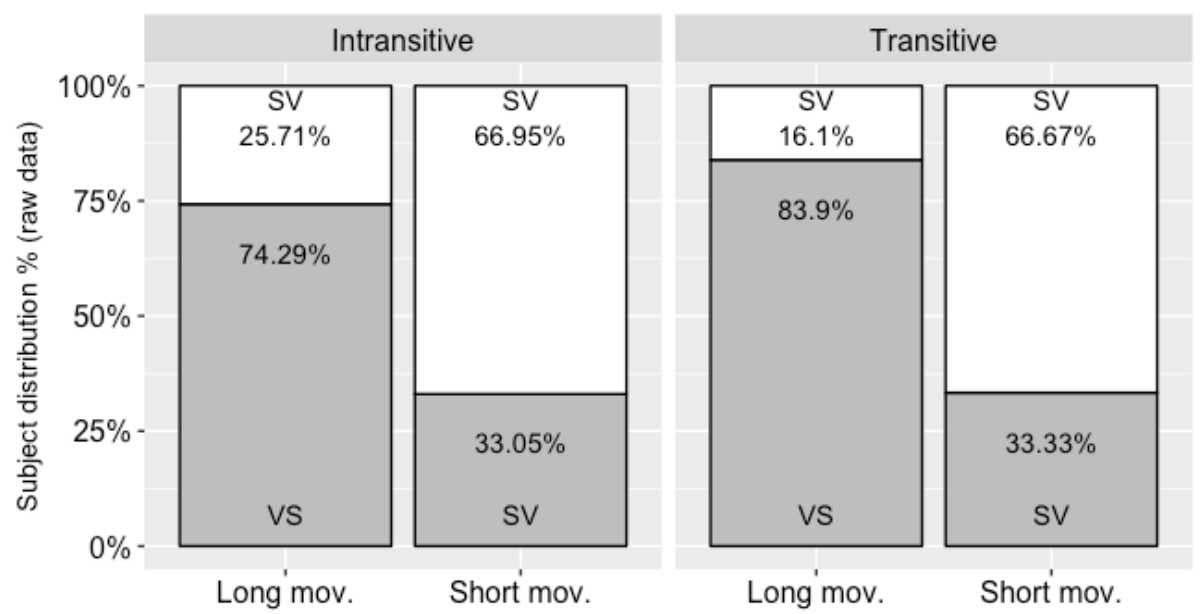

Figure 2: Preferences of SV vs. VS across type of dependency and type of verb

We carried out statistical analyses based on multi-level mixed effects regressions with log odds of a postverbal subject response as the dependent variable, type of movement (short vs. long wh-movement) and type of VP (transitive vs. intransitive) as fixed effects. The best random structure justified by the data included random intercepts for subjects and items, as well as bysubject and by-item random slopes for the effect of movement type and bysubject random slopes for the type of verb. For both fixed factors, we specified the contrasts with a deviation coding scheme.

The type of wh-movement (short vs. long) has a significant impact on the preference for the position of the embedded subject: under the long whmovement condition the probability of postverbal subject is significantly higher than under the short wh-movement condition (Estimate=2.63, SE=.228, $\mathrm{p}<.001$ ). The main effect of VP type is not significant (Estimate $=.40, \mathrm{SE}=.270$, p>.1). However, the interaction between type of movement and type of verb approaches to the significance threshold (Estimate $=0.632, \mathrm{SE}=.354, \mathrm{p}=.074$ ), indicating that the probability for postverbal subjects is higher for transitive verbs than intransitives in case of long-distance movement. We extracted the coefficients and the confidence intervals (calculated at 0.95) from the model, and converted them to estimated probabilities, plotted in in Figure 3. 

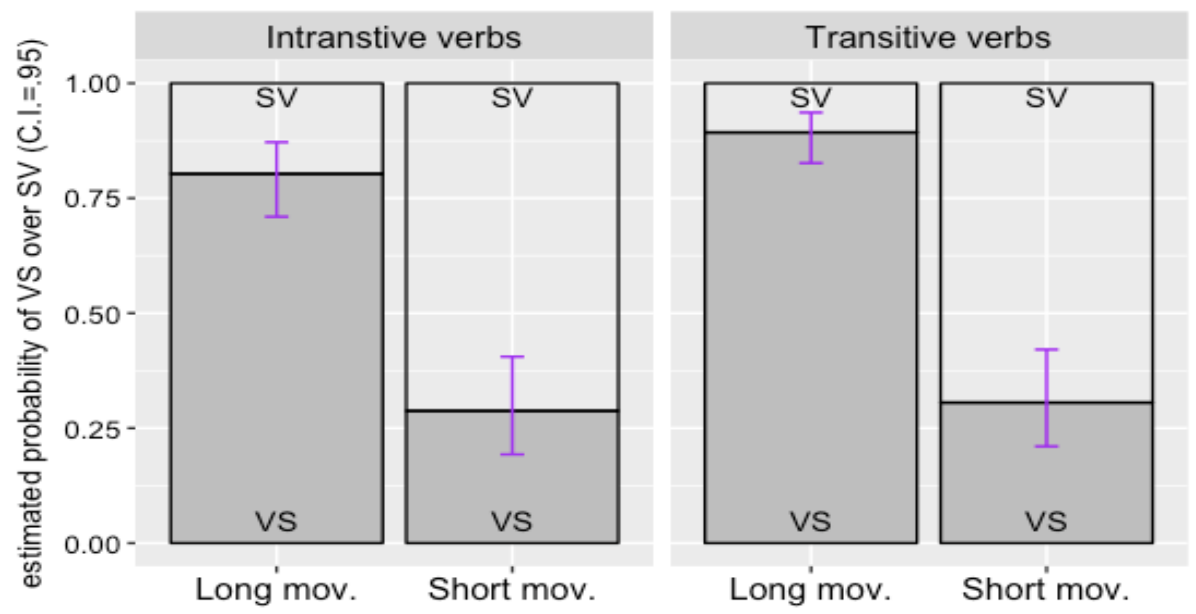

Figure 3: Estimated probabilities for VS over SV across type of dependency and type of verb

\subsection{Lack of ceiling effect: some remarks}

If on the one hand, the results of the syntactic experiment confirm subject inversion with long extraction, on the other, the lack of ceiling effect is evident and raises important questions: why is SV still chosen in $21 \%$ of the longmovement cases? Two possible answers come to mind. It could be that the deviant pattern is simply the consequence of the structural complexity of whquestion with long extraction: this would imply that our participants fail to interpret correctly the relevant experimental stimuli in the corresponding number of cases (i.e. 21\%). Alternatively, it could well be that the preference for SV is not to be attributed to a processing difficulty, but rather to a different interpretation of the preverbal subject that would still be compatible with the long-distance interpretation. Even if we specifically tried to control for (and prevent from) such an interpretation (by avoiding any mention of the subject in the introductory context and, hence, that it could be interpreted as a given), it could be that, in this smaller percentage of the cases, the preverbal subject was perceived as left-dislocated, namely, in a TopP position. Given that order Topic $>$ wh>verb is always possible, a topical subject in TopP would not intervene between the wh-trace in the embedded $\mathrm{CP}$ and the lower verb. As an alternative, we tentatively suggest that the adjacency requirement is somewhat weaker when the (intermediate) movement to $\mathrm{CP}$ is triggered by a formal rather than a criterial feature (see Rizzi 2006 for the distinction between formal and criterial features). 
A similarly lack of ceiling effect can be observed with short extraction: even when the wh-phrase is not extracted from the embedded clause, VS is preferred in the $33 \%$ of the cases. Again, we unfortunately do not have a sound solution to this issue. Before pursuing a more solid analysis of both deviant patterns, more experimental evidence is needed. For the time being, we leave this task for future work.

\section{Moving through the phase edges: Our analysis}

Building on Calabrese's original insights, we offer an analysis that simultaneously account for both embedded subject inversion and the placement of NPA. In fact, we propose that both phenomena are the reflexes of successive cycle movement and, more specifically, under the current minimalist theory, of the Phase Impenetrability Condition (Chomsky 2008), according to which whmovement must pass through the edge of every $v \mathrm{P}$ and $\mathrm{CP}$ phase between the base-generation position and the final landing site. We additionally assume that, in direct wh-questions, an interrogative wh-phrase bears a wh/focal feature and that, when it passes through the edge of a phase $\left(\mathrm{v}^{\circ}\right.$ or $\left.\mathrm{C}^{\circ}\right)$, the wh-phrase shares wh/focal feature with the relevant phase head. This is how the wh-phrase in its final position and the lexical verb - or verbs in case of long distance movementend up forming the main intonational phrase of the sentence: all elements are specified for the same wh/focal feature, and NPA is assigned to a syntactic element that bears this feature, whether interpretable or not (see BBC 2017)

This analysis correctly predicts that an embedded verb is visible to phonology for the assignment of NPA only in case of long distance movement, given that the wh-phrase must move through the edge of the $v$ phase head. By contrast, only the matrix verb is a possible candidate for NPA assignment because no feature sharing occurs in the embedded clause.

If the intermediate movement through the edge of the $\mathrm{vP}$ is responsible for the distribution of NPA, we argue that intermediate movement through the edge of the CP triggers subject inversion. Whether or not this is to be related to the Wh-Criterion and to T-to-C movement -we leave this question open for future research- the intermediate passage of the wh-phrase through the edge of the Cphase, prevents subjects from moving to their regular preverbal position in the TP domain (i.e. SubjP). Embedded subjects must therefore occur in a lower position, that is, in a subject inversion configuration.

\section{Further observations and experimental evidence}

As mentioned in the previous section, along the lines of Calabrese (1982) and Torrego $(1983,1984)$ (cf. § 2.2), we claim that subject inversion (VS) with long extraction is determined by successive cyclic movement, i.e. the transitory movement of the wh-phrase to the embedded left periphery (the edge of the 
$\mathrm{C}^{\circ}$ ). Our analysis, more specifically, put together elements from both Calabrese's phonological account and Torrego's syntactic proposal. We do subscribe to the idea that the verb (or the verbs in case of long distance movement) form a single intonational phrase and that the NPA is assigned to its rightmost constituent. ${ }^{9}$ Unlike Calabrese, however, and following more closely the Torrego's insight, we argue that embedded subject inversion is a direct reflex of the syntactic derivation, i.e. successive cyclic movement, rather than prosodic well-formedness requirements as in Calabrese's analysis. In particular, we propose that the same mechanism that triggers subject inversion in matrix clauses and that makes SubjP unavailable to (preverbal) subjects (cf. $\S 2.1$ ) also operates in embedded clauses. Our analysis relies on three empirical observations, each supported by the relevant experimental data:

(i) in direct wh-questions with bare wh-elements, NPA is by default assigned to the lexical verb; it is assigned to the embedded lexical verb only with long-distance movement;

(ii) in indirect wh-questions, NPA is not assigned to the verb, but to the rightmost constituent of the sentence, unless a constituent that qualifies as narrow focus attracts the NPA;

(iii) subject inversion also occurs in indirect wh-questions.

A direct and close comparison between the syntax and the prosody of direct and indirect wh-questions, show that embedded subject inversion in direct whquestions with long extraction cannot be triggered by a prosodic requirement on focussed elements because inversion also takes place in indirect questions where a different prosodic contour is can be observed (see also Bocci \& Pozzan 2014). We devote the rest of this section to the three observations mentioned above, whose discussion will lead us to a more precise definition of the phenomena in support of our proposal based on successive cyclic movement and feature sharing in intermediate positions.

\subsection{NPA assignment in direct wh-questions}

The assignment of NPA in wh-questions is a constraint that has not yet been fully understood or accounted for. In line with a widespread view (e.g. Horvath 1981/1986, É. Kiss 1995; see Haida 2007: §7.2 for an overview), Calabrese (1982) argues that the wh-element in wh-questions is endowed with a focus feature on a par with the focus constituent of declaratives. However, while in assertions the focus constituent must bear the main prominence of the sentence, in wh-questions NPA falls on to the verb, especially when the question contains a non-D-linked wh-phrase (in the sense of Pesetsky 1987). This implies that the

\footnotetext{
${ }^{9}$ For the time being, we remain agnostic on the exact definition of the prosodic constituent that including the verb(s) and the wh-phrase.
} 
verb carries NPA even when it is not interpreted as focus. To account for this syntax-prosody mismatch, Calabrese proposes an analysis based on two assumptions (cf. §2.2): (i) the focus feature is assigned to the wh-phrase in its base-generated position, connected to the surface position by means of a $\mathrm{A}^{\prime}-$ chain and thus guaranteeing the correct interpretation; (ii) the main pitch accent of the sentence is then assigned to the last phonological phrase within the main intonational phrase, i.e. the prosodic unit made up by the wh-phrase and the adjacent verb.

BBC (2017) substantiate this observation through the results of a dedicated production experiment aimed at investigating the placement of NPA in whquestions. Ten native speakers of Tuscan Italian had to read 24 stimuli (12 pairs), alternating short-distance wh-movement (9a) and long-distance whmovement (9b), together with 24 fillers (=12 pairs), which were presented in a pseudo-randomized order:

(9) a. Chi pensa che ti dovrei presentare al direttore? who thinks that you should.1SG introduce to-the director 'Who thinks that I should introduce you to the director?'
b. Chi pens
che dovrei
presentare al direttore?
who think.2SG that should.1SG introduce to-the director
'Who do you think that I should introduce to the director?'

The results show that, in complex wh-questions consisting of a matrix and an embedded clause, the NPA is assigned to the verb, either to the main lexical verb or to the embedded lexical verb. NPA on the wh-element is totally marginal (cf. Fig.4). In particular, the experimental findings demonstrate that, with long-distance movement (9b), NPA is much more likely to be associated with the lexical verb of the embedded clause, rather than the matrix lexical verb (cf. Fig. 5). By contrast, when the wh-element is extracted from the matrix clause, via short-distance movement (9a), NPA is assigned to the lexical verb of the matrix clause (cf. Fig. 6). 


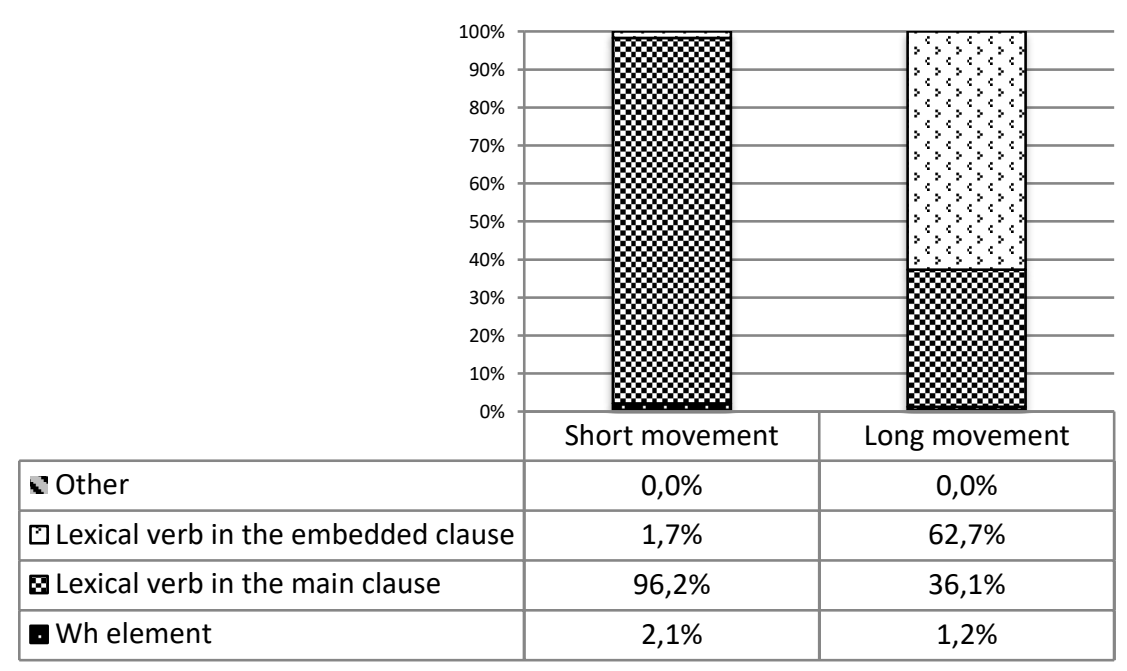

Figure 4: Distribution of NPA across type of wh-movement

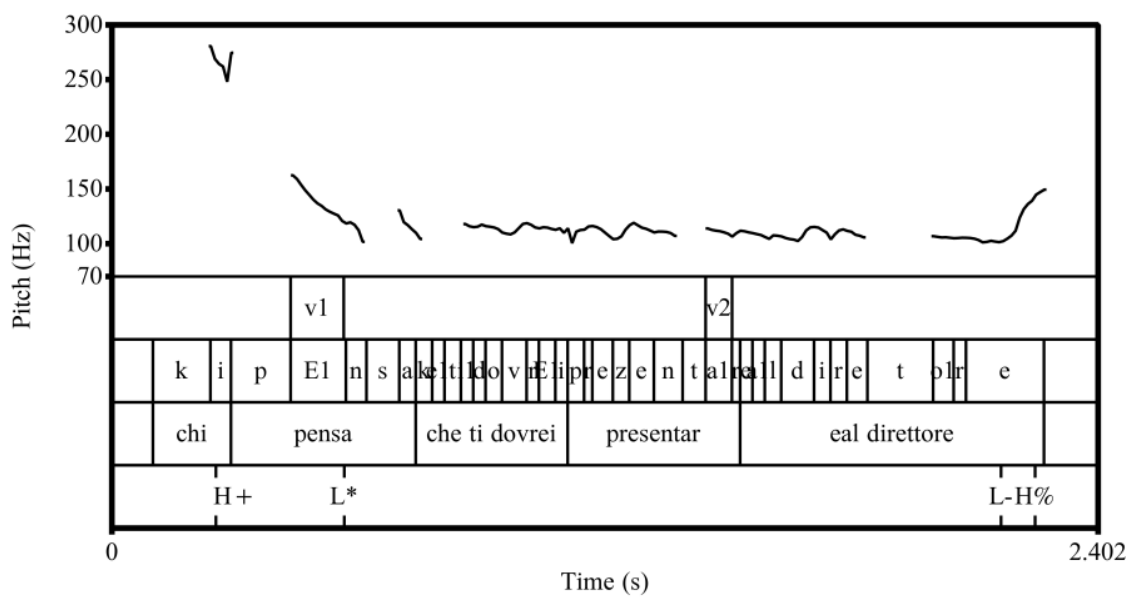

Figure 5: Pitch contour of the wh-question with short movement in (9a) 


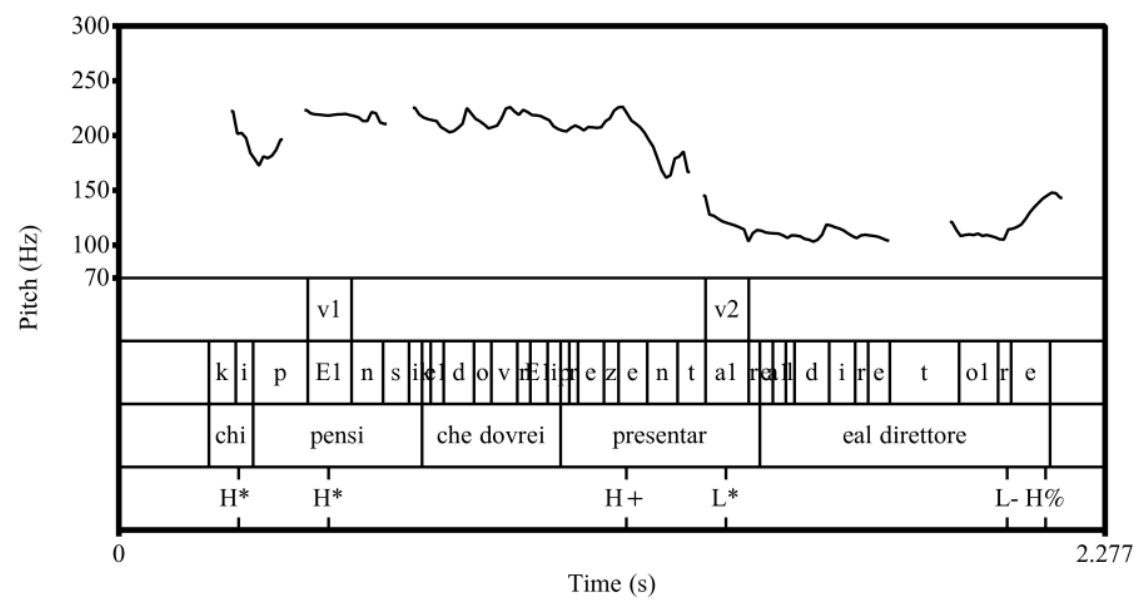

Figure 6: Pitch contour of the wh-question with long movement in (9b)

Crucially, as shown in Fig. 4, NPA is virtually never assigned to the embedded lexical verb (only $1.7 \%$ ), and in both conditions it is in fact never $(0 \%)$ assigned to the rightmost element of the sentence, which is the default position for NPA assignment in Italian. We refer to BBC 2017 for more details on the experiments and on the results. ${ }^{10}$

\subsection{NPA assignment in indirect wh-questions}

Since Calabrese's account connects subject-inversion in wh-questions with the special prosodic properties of wh-questions, we tested the same two properties in indirect wh-questions. In this section we discuss the evidence for the prosodic properties of indirect wh-questions from a production experiment, while in the next section we report the results of forced-choice experiment on the distribution of the subject in indirect wh-questions.

We carried out a production experiment with 10 native speakers of Tuscan Italian ( 8 women, 2 men) who had to read short scripts. Each script consisted of a description of a fictional context followed by a target indirect question. The experiment comprised of 24 stimuli divided into three groups on the basis of the wh-phrase being tested: 8 stimuli with direct object chi 'whom' as, 8 with indirect object $a$ chi 'to whom', and 8 with locative dove 'where'. We collected 4 repetitions for each trial. Out of the produced sentences we randomly picked

${ }^{10}$ See BBC (2017) also for arguments and evidence against Calabrese's idea that the syntactic element relevant to the definition of the main intonational phrase at the syntax/phonology interface is the wh-trace in its base-generation position. 
2 disfluency free repetitions, whenever available, for the prosodic analysis and discarded the sentences that included disfluency (and false starts). The overall corpus analysed thus consisted of 480 indirect wh-questions: 10 speakers $* 24$ items $* 2$ disfluency-free repetitions.

The 24 stimuli were pseudo-randomized, ensuring a rigid alternation between experimental stimuli and an equal number of fillers. We downsampled the sentences from $48 \mathrm{kHz}$ to $16 \mathrm{kHz}$, and automatically segmented them into phonemes by means of WebMAUS aligner (Schiel 1999, Kisler et al. 2016)the segmentation was then carefully corrected manually. We transcribed the sentences intonationally. In particular we labelled as NPA the rightmost PA after which the pitch contour is completely compressed and no fully-fledged PA is observable (Gili Fivela \& al. 2016). The following results emerged from our experiment.

Under neutral conditions, in indirect wh-questions, NPA is assigned to the rightmost constituent of the sentence. The prosodic contour of an indirect whquestion with $a$ chi 'to whom' is illustrated in Fig. 7. The sentence reads: Vorrei sapere a chi abbiano negato il prepensionamento 'I'd like to know whom they deny an early retirement to'.

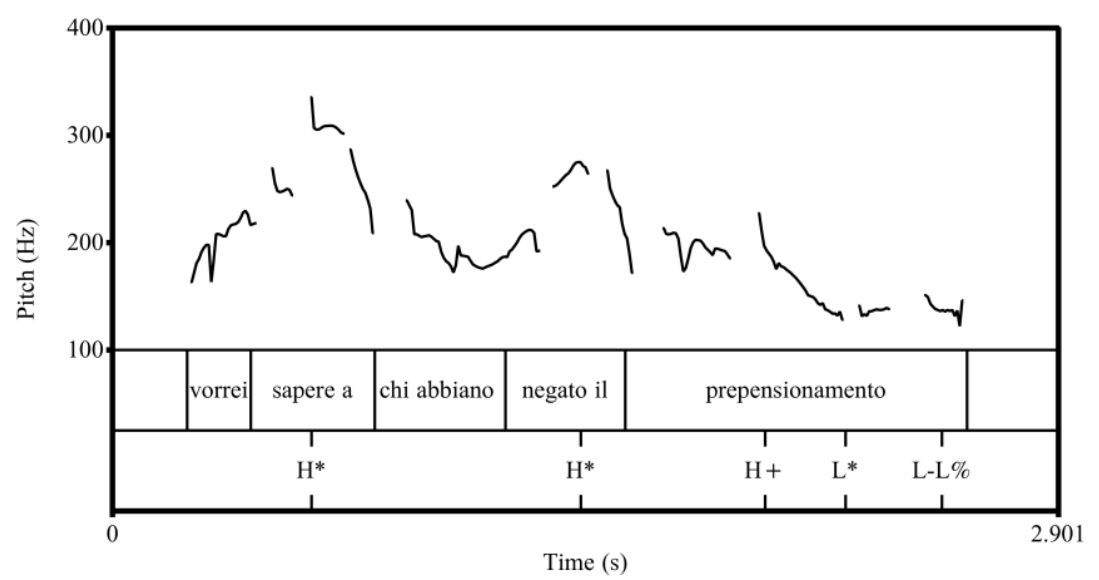

Figure 7: Pitch contour of an indirect wh-question

In Fig. 7, we observe that the NPA $\mathrm{H}+\mathrm{L}^{*}$ falls on the stressed syllable of the rightmost constituent of the sentence. Crucially, this corresponds to the default prominence placement for Italian declaratives. In fact, the NPA is virtually never assigned to the verb as it happens in direct wh-questions (cf. § 5.2). Our findings, therefore, lead us to the generalization that the prosody of indirect whquestions patterns with that of declarative sentence rather than with the prosody of direct wh-questions. 


\subsection{Subject inversion in indirect wh-questions}

In the previous section, we saw that in indirect wh-questions, NPA is not necessarily assigned to the verb or to the wh-element: in other words, in this environment, Calabrese's phonological requirement is not at play. Subject inversion, nevertheless, systematically occurs in indirect wh-questions. Bocci \& Pozzan (2014) investigated the distribution of subjects in main and indirect questions. On the basis of three experimental studies, Bocci \& Pozzan (2014) shows the that when the discourse disallows a topic or narrow focus interpretation of the subject, post-verbal subjects are preferred and rated more highly than pre-verbal subjects in questions with dove 'where', while the reversed pattern is found in wh-questions with perché 'why' and yes-no questions. These patterns were observed both in main and indirect questions.

The distinct behaviour of perché 'why' as opposed to the other wh-phrases is expected in light of the existing literature. Perché is base-generated in the left periphery and does not undergo wh-movement (Rizzi 2001), while dove 'where', which we chose as representative of the class of bare wh-phrases that also include who, what, how, undergoes wh-movement to the embedded left periphery and thus triggers subject inversion. Similarly, indirect yes/noquestions introduced by se 'if' do not involve wh-movement and do not induce subject inversion. In conclusion, since subject inversion is observed in indirect wh-questions and since the indirect questions are not characterized by the same special prosodic properties of main wh-questions, subject inversion cannot be triggered by a prosodic requirement.

The indirect questions tested in Bocci \& Pozzan's (2014) had indicative mood. Even if the indicative is not the favourite option for most speakers in this context, it is generally accepted at the colloquial level. However, the subjunctive is prescriptively required and often preferred by native speakers in indirect questions, although there is a strong variability across speakers. Relevantly, the mood of the embedded verb has been reported to have an impact on the subject position, as observed by Calabrese (1982: 66-67) himself, and to play a relevant role in the licensing of preverbal subjects (see Rizzi 1996, 2001, Giorgi \& Pianesi 1997, Poletto 2000). Consequently we wanted to assess the different impact of the subjunctive mood and thus carried out a web-based two-alternative forced choice experiment using similar materials as in Bocci and Pozzan's (2014) experiment and taking the mood of the embedded verb as a factor. Unlike in Bocci and Pozzan's study, we only considered indirect questions in this study.

The two experimental factors were: (i) 'embedded mood' with two levels, i.e. indicative vs. subjunctive, and (ii) 'question type' with three levels: whquestion with dove 'where', wh-questions with perché 'why', and yes/no- 
questions introduced by $s e$ 'if'. ${ }^{11}$ The two factors were manipulated within items in a fully crossed design. We tested 30 items under 6 conditions $(=3 * 2)$, leading to a total of 180 target sentences. For each target sentence, we had two versions: with the subject of the embedded clause either in preverbal or in postverbal position. All target sentences consisted of indirect questions in which the embedded clause contained only a subject (full DP) and an unergative verb in present (syncretic) tense. Here below are examples for each condition:
A: Perché non metti un po’ di musica?
'Why don't you put some music on?'
[dove, indicative]
B: Meglio di no. Non so dove Claudia studia.
B'. Meglio di no. Non so dove studia Claudia. (VS) better of not not know where Claudia studies Claudia
'Better if I don't. I don't know where Claudia studies/is studying.'
A: Perché non metti un po' di musica?
'Why don't you put some music on?'
[dove, subjunctive]
B: Meglio di no. Non so
dove Claudia studi.
B'. Meglio di no. Non so dove studi Claudia. (VS)
better of not not know where Claudia studies Claudia
'Better if I don't. I don't know where Claudia studies/is studying.'

(12) A: Ma gli esami non sono stati rinviati?

'Haven't the exams been postponed?'

[perché, indicative]

B: Sì, di due mesi. Non so perché Claudiastudia.

B'. Sì, di due mesi. Non so perché studia Claudia. yes of two months not know why Claudiastudies Claudia

'Yes, of two months. I don't know why Claudia studies/is studying.'

(13) A: Ma gli esami non sono stati rinviati?

'Haven't the exams been postponed?'

[perché, subjunctive]

B: Sì, di due mesi. Non so perché Claudiastudi.

B'. Sì, di due mesi. Non so perché studi Claudia.

yes of two months not know why Claudiastudies Claudia

(VS)

'Yes, of two months. I don't know why Claudia studies/is studying.'

$$
\text { A: Perché non metti un po' di musica? }
$$

[se, indicative]

\footnotetext{
${ }^{11} \mathrm{We}$ added this latter type of question, namely, if-questions, to see which positions subjects occupy within indirect yes/no-questions. Since this article deals with whquestions, we will not comment on the results and on their theoretical implications. See Bocci \& Pozzan (2014) for discussion.
} 
'Why don't you put some music on?'

B: Meglio di no. Non so se Claudia studia. (SV)

B'. Meglio di no. Non so se studia Claudia. (VS)

better of not not know if Claudia studies Claudia

'Better if I don't. I don't know if Claudia studies/is studying.'

(15) A: Perché non metti un po' di musica?

'Why don't you put some music on?'

[se, subjunctive]

B: Meglio di no. Non so se Claudia studi. (SV)

B'. Meglio di no. Non so se studi Claudia. (VS)

better of not not know if Claudia studies Claudia

'Better if I don't. I don't know if Claudia studies/is studying.'

The target sentences were divided in 6 lists following a Latin square design. The two factors 'embedded mood' and 'question type' were manipulated within participants, so that each list consisted of 30 experimental item. Each participant was thus presented with the experimental stimuli of a certain item only under one condition. 30 fillers were added to the trials, and the order of the trials was pseudo-randomized. The experimental trials and the fillers alternated.

The pairs of sentences were presented as parts of brief written exchanges between two speakers (A and B) (cf. 10-15). The contexts were designed in order to disfavour as much as possible a focus or topic interpretation of the subject of the embedded clause. For each item, se-questions and dove-questions were presented within the same dialogue, while perché-questions were introduced by different dialogues. Participants were asked to choose between the two alternative orders (SV vs. VS); 60 native speakers of Italian residing in Italy volunteered the experiment.

Fig. 8 shows the results: 

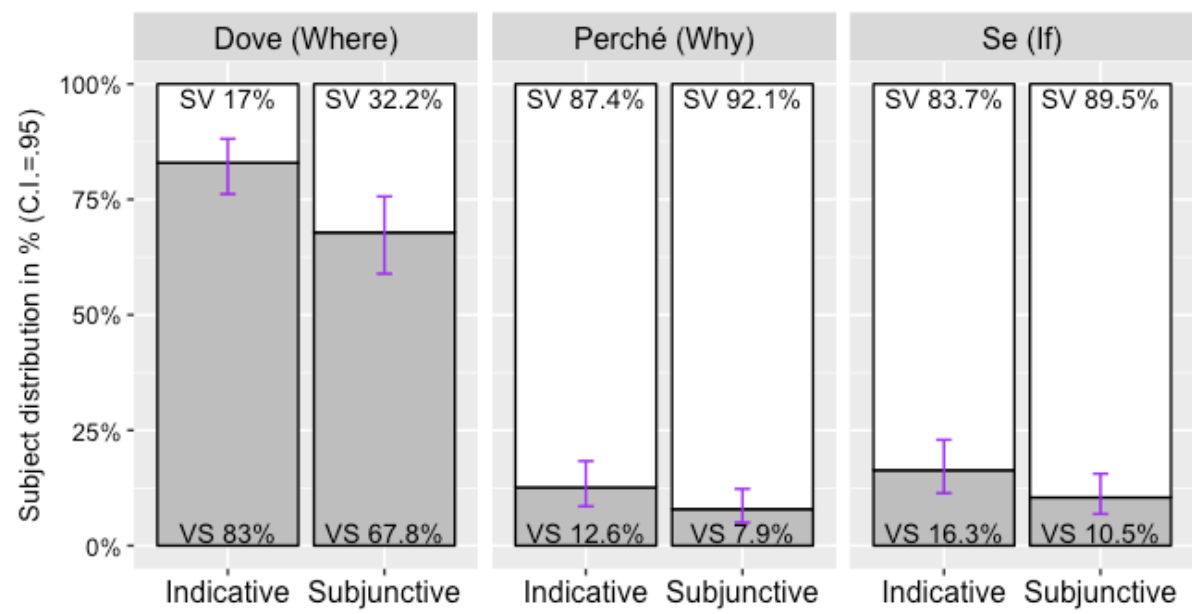

Figure 8: Preferences for VS in the three question types

Statistical analyses were based on multi-level mixed effects regressions with $\log$ odds of a post-verbal subject response as the dependent variable, mood (subjunctive vs. indicative), question-type (se-, perché-, and dove-questions) as fixed effects. The random structure included by-subject and by-item random intercepts, and by-subject and by-item slopes for question-type.

A first statistical model, with question-type specified with backward difference schema, showed that subject distribution in se- and perché-questions is not significantly different (Estimate $=-.560, S E=.36, \mathrm{p}>.1$ ), while perché-questions significantly differ from dove-questions (Estimate $=4.043, \mathrm{SE}=.438, \mathrm{p}<.001$ ). The main effect of mood was extremely significant (Estimate $=.009, \mathrm{SE}=.2$, $\mathrm{p}<.001)$. To understand the role of the mood with respect to perché-questions and dove-questions, we fitted a second model that included only perché- and dove-questions. This model revealed that dove-questions with subjunctive mood (the baseline) significantly differ from dove-questions with indicative mood (Estimate $=1.112, \mathrm{SE}=.271, \mathrm{p}<.001)$ since in latter condition the preference for post-verbal subjects increases. Notably, dove-questions with subjunctive mood significantly differ also from perché-questions with subjunctive mood (Estimate $=-3.724, \mathrm{SE}=.488, \mathrm{p}<.001$ ) since the probability of VS in the latter condition is much lower. There is no marginal interaction for perché-questions with indicative mood (Estimate $=-.595, \mathrm{SE}=.0 .444, \mathrm{p}>.1)$ indicating that the type of mood does not affect the distribution of subjects in perché-questions.

These results show that, in contexts that disfavour a focus and topic interpretation, postverbal subjects are clearly preferred in dove-questions, but dispreferred with why-and se-questions. The pattern observed in the indicative 
is present in the subjunctive: although the inverting effect of dove is slightly reduced with subjunctive, VS is still the prevailing pattern in dove questions with the subjunctive and this contrasts with the preference observed for perchéquestions with the same mood. Cf. Fig. 8.

In conclusion, we have experimental evidence tha the subjunctive slightly diminish the preference for preverbal subjects in indirect questions. However, even if less compelling, exactly the same preference patterns observed with the indicative are reproduced with the subjunctive, showing that the factor that really counts is the question type.

\section{Conclusion}

The derivational history of the wh-phrase, i.e. its successive cyclic movement, is essential to understand the constraints on the subject position and on the placement of NPA, in wh-questions both with short and long movement. Our first experiment shows that subject inversion in the embedded clause of a complex wh-question is strongly preferred only when the wh-phrase originates from within that clause and has then moved to the main clause. Our further experimental data (see in particular BBC 2017) add prosodic evidence in favour of the crucial role of the successive cyclic movement in the determination of the syntactic and prosodic properties of wh-questions. Our results confirm that in complex wh-questions the placement of NPA is sensitive to the extraction site of the wh-element. The differences and similarities between direct and indirect wh-question are crucial in this respect. On the one hand, the adjacency requirement between the wh-element and the verb is active in main whquestions as well as in indirect wh-questions, both with the subjunctive and the indicative mood. On the other, with respect to their prosodic properties, indirect wh-questions pattern with declarative sentences rather than with direct whquestions, insofar as the nuclear pitch accent is placed by default on the rightmost element of the sentence.

We thus conclude that subject inversion in wh-questions does not result from a prosodic requirement, but rather has a syntactic nature. While there is no direct cause relation between NPA placement and subject inversion, both phenomena are independently rooted in the syntactic computation. Subject inversion in both main and indirect questions is a syntactic phenomenon and is sensitive to successive cyclic movement. Similarly, NPA placement in direct wh-questions is syntactically determined and is also a reflex of successive cyclic movement. 


\section{References}

Belletti, A. 2004. Aspects of the low IP area. In The Structure of IP and CP. The Cartography of Syntactic Structures, Vol. 2, L. Rizzi (ed.), 16-51. Oxford: Oxford University Press.

Bocci, G. \& L. Pozzan. 2014. Questions (and experimental answers) about Italian subjects. Subject positions in main and indirect question in L1 and attrition. In C. Contemori and L. Dal Pozzo (eds.), Inquiries into Linguistic Theory and Language Acquisition. Papers offered to Adriana Belletti, Siena : CISCL Press.

Bocci, G. 2013. The Syntax-Prosody Interface: A cartographic perspective with evidence from Italian. Amsterdam: John Benjamins.

Bocci, G., Bianchi, V. \& S. Cruschina. 2017. Prosody tracks cyclic movement: evidence from Italian wh-questions. Ms.

Calabrese, A. 1982. Alcune ipotesi sulla struttura informazionale della frase in Italia- no e sul suo rapporto con la struttura fonologica. Rivista di Grammatica Generativa 13: 489-526.

Cardinaletti, A. 2001. A second thought on emarginazione: Destressing vs 'Right Dislocation'. In Current Studies in Italian Syntax. Essays offered to Lorenzo Renzi, G. Cinque \& G. Salvi (eds.), 117-135. Amsterdam: Elsevier.

Cardinaletti, A. 2002. Against optional and null clitics. Right dislocation vs. marginalization. Studia Linguistica 56 (1): 29-57.

Cardinaletti, A. 2007. Subjects and wh-questions. Some new generalizations. In J. Camacho et al. (eds.), Romance Linguistics 2006: Selected papers from the 36th Linguistic Symposium on Romance Languages (LSRL), John Benjamins, 57-79.

Chomsky, N. 2008. On phases. In Robert Freidin, Carlos P. Otero, and Maria Luisa Zubizarreta (eds.), Foundational issues in linguistic theory: Essays in honor of Jean-Roger Vergnaud. Cambridge, MA: MIT Press.

Giorgi, A. \& F. Pianesi. 1997. Tense and Aspect. From Semantics to Morphosyntax. Oxford/New York: Oxford University Press.

Kisler T., Reichel U., Schiel F., Draxler C., Jackl B. \& Pörner N. 2016. BAS Speech Science Web Services - an Update of Current Developments. In Proceedings of the 10th International Conference on Language Resources and Evaluation (LREC 2016), Portorož, Slovenia, pp. 38803885.

Munaro, N. 201. La frase interrogativa. In Grammatica dell'italiano antico, L. Renzi \& G. Salvi (eds.), 1147-1185. Bologna: Il Mulino.

Norvin, R. 2010. Uttering Trees. Cambridge, MA: MIT Press.

Norvin, R. 2016. Contiguity Theory. Cambridge, MA: MIT Press.

Pesetsky, D. 1987. Wh-in-situ: Movement and unselective binding. In E. Reuland \& A. ter Meulen (eds.), The representation of (in)definiteness. Cambridge, MA: MIT Press, 98-129. 
Poletto, C. 2000. The Higher Functional Field: Evidence from Northern Italian Dialects. Oxford/New York: Oxford University Press.

Rizzi, L. \& U. Shlonsky. 2007. Strategies of Subject Extraction. In H.-M. Gärtner \& U. Sauerland (eds.), Interfaces + Recursion = Language? Chomsky's Minimalism and the View from Syntax-Semantics, 115-160. Berlin: Mouton de Gruyter.

Rizzi, L. 1996. Residual Verb-second and the Wh-criterion. In Adriana Belletti \& Luigi Rizzi (eds), Parameters and Functional Heads. Essays in Comparative Syntax. Oxford/New York: Oxford University Press, 6390.

Rizzi, L. 2001. On the position Int(errogative) in the left periphery of the clause. In G. Cinque \& G. Salvi (eds.), Current studies in Italian syntax. Essays offered to Lorenzo Renzi, 287-296. Amsterdam: Elsevier.

Rizzi, L. 2006. On the Form of Chains: Criterial Positions and ECP Effects. In Wh-Movement. Moving On. Lisa Lai-Shen Cheng and Norbert Corver (eds.), 97-133. Cambridge, Mass.: MIT Press.

Schiel, F. 1999. Automatic Phonetic Transcription of Non-Prompted Speech. Proc. of the ICPhS 1999: 607-610.

Torrego, E. 1983. More effects of successive cyclic movement. Linguistic Inquiry 14: 561-565.

Torrego, E. 1984. On inversion in Spanish and some of its effects. Linguistic Inquiry 15: 103-129. 